William G. Dewald

Willam G. Dewald is deputy director, Planning and Economic Analysis Staff, at the Department of State. This paper, the second annual Homer Jones Memorial Lecture, was presented at St. Louis University on May 6, 1988. Views expressed are the author's own and do not represent the U.S. Department of State or the federal government.

\title{
Monetarism Is Dead; Long Live the Quantity Theory
}

N OCTOBER 1979, when the Federal Open Market committee adopted new operating procedures purported to be directed at control of monetary aggregates, newspapers reported that economists at the Federal Reserve Bank of St. Louis celebrated. Many had been hired and inspired by Homer Jones, its former research director, to whose memory this lecture is dedicated. The celebration was premature.

Those new procedures were a cover for genuinely restrictive policy actions that reversed the upward ratcheting of inflation begun in the $1960 \mathrm{~s}$. It threatened to get out of hand in 1979. Such a policy reversal was altogether appropriate, but, as in earlier episodes, it represented an abrupt shift in direction made necessary because earlier policy had taken the economy so far off course. Whether or not the Federal Reserve genuinely attempted to control growth in the monetary aggregates beginning in 1979 , it no longer does. The reason is not that it could not, but that the relationship between growth in the aggregates and GNP, and in turn inflation, appeared so unpredictable. Consequently, in recent years the Federal Reserve has reverted to manipulating open market purchases and sales of securities to hold federal funds rates or free reserves within target ranges as was the practice from the 1920 s until 1979 .
In 1961, soon after leaving the Federal Reserve Bank of Minneapolis, I gave a talk there in which I criticized Federal Reserve operating procedures for focusing on free reserves or interest rates rather than growth in the monetary aggregates. The Federal Reserve was characterized as a baseball player who can't hit a curve. He swings at where the ball was, not where it is. The example I cited was the experience in 1960 when the Federal Reserve persisted in targeting lower and lower interest rates even as monetary growth turned negative and the economy slipped into recession.

The Chairman of the Board of Governors of the Federal Reserve in those days was William McChesney Martin. He likened the role of monetary policy to "leaning against the wind," the idea being that money market conditions as measured by interest rates or free reserves would tighten during business expansions and ease during contractions. In 1988, the Federal Reserve no longer tightens, it snugs. Whatever the name, there is a problem with this apptoach. Even if the Federal Reserve takes no action, interest rates can change because of changes in total spending in the economy and associated credit demands. The risk is that the Federal Reserve will attribute a decline in interest rates, as it did in 1960 , to its policies when in fact by not selecting a low enough interest rate 


\section{Chart 1}

GNP Deflator

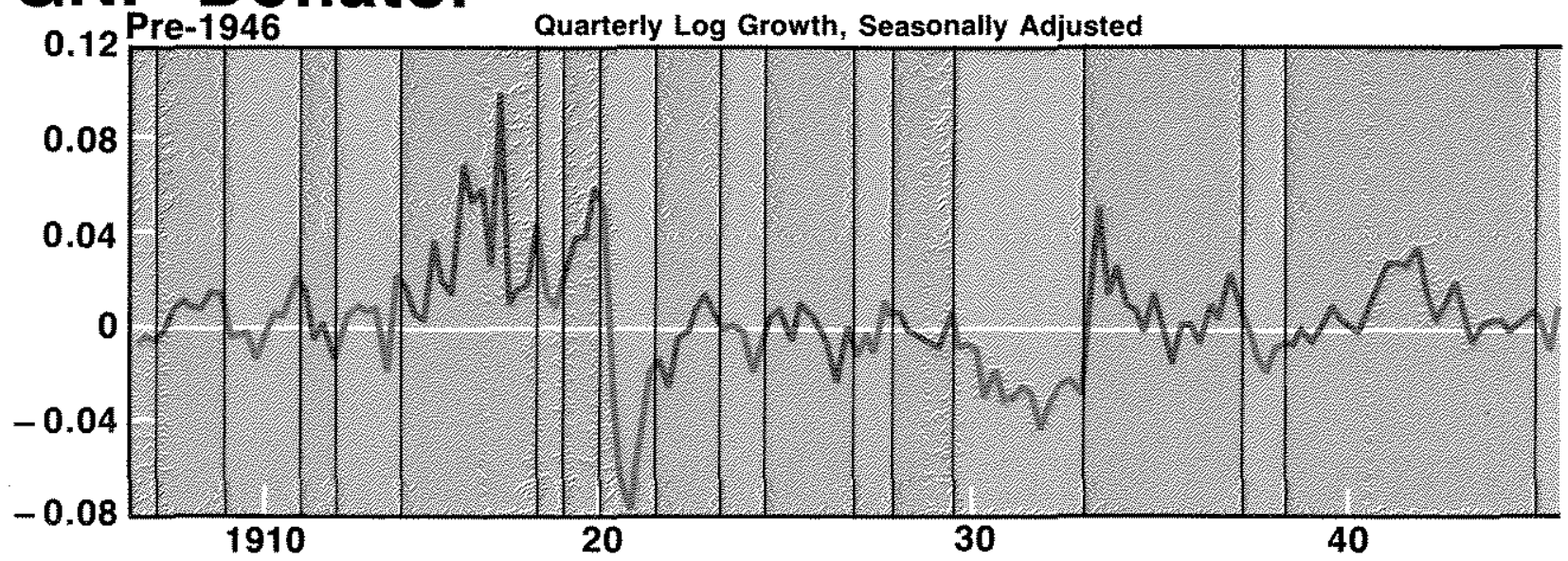

Chart 2

Real GNP

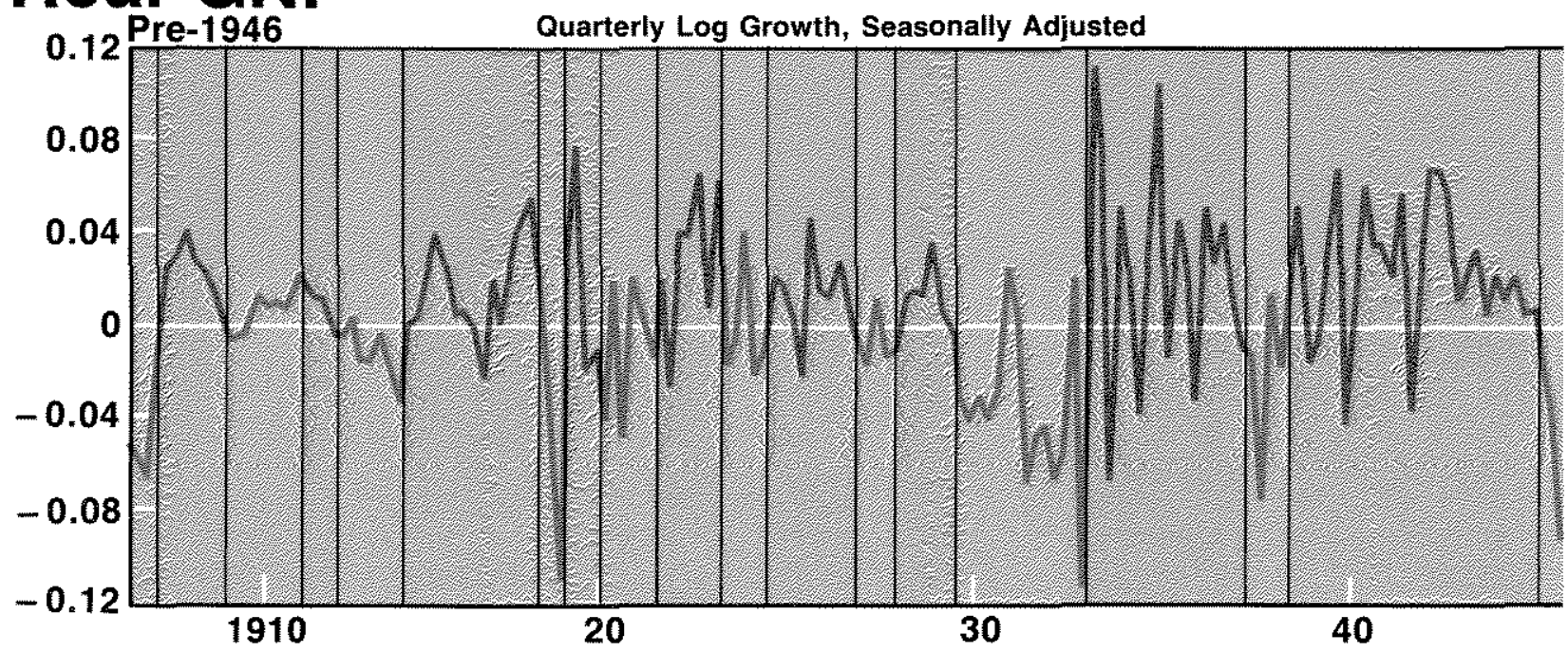

Chart 3

Nominal GNP

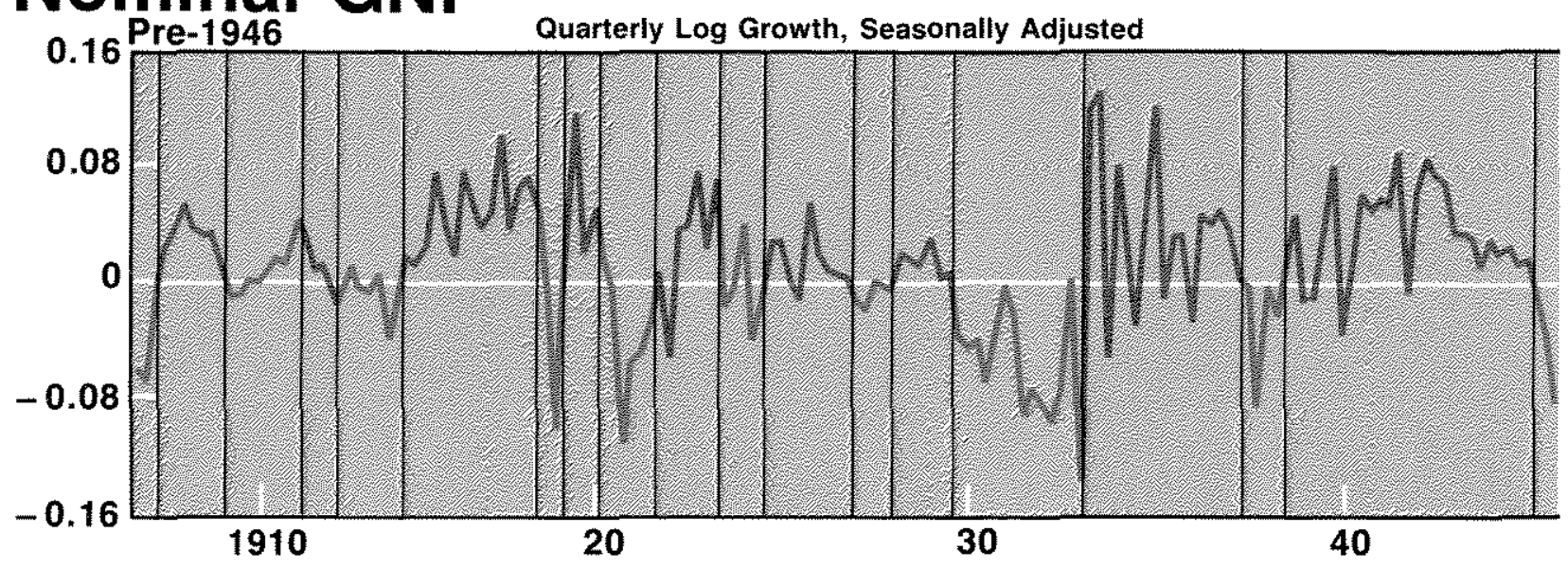

Quafterly Log Growth, Seasonally Adjusted 

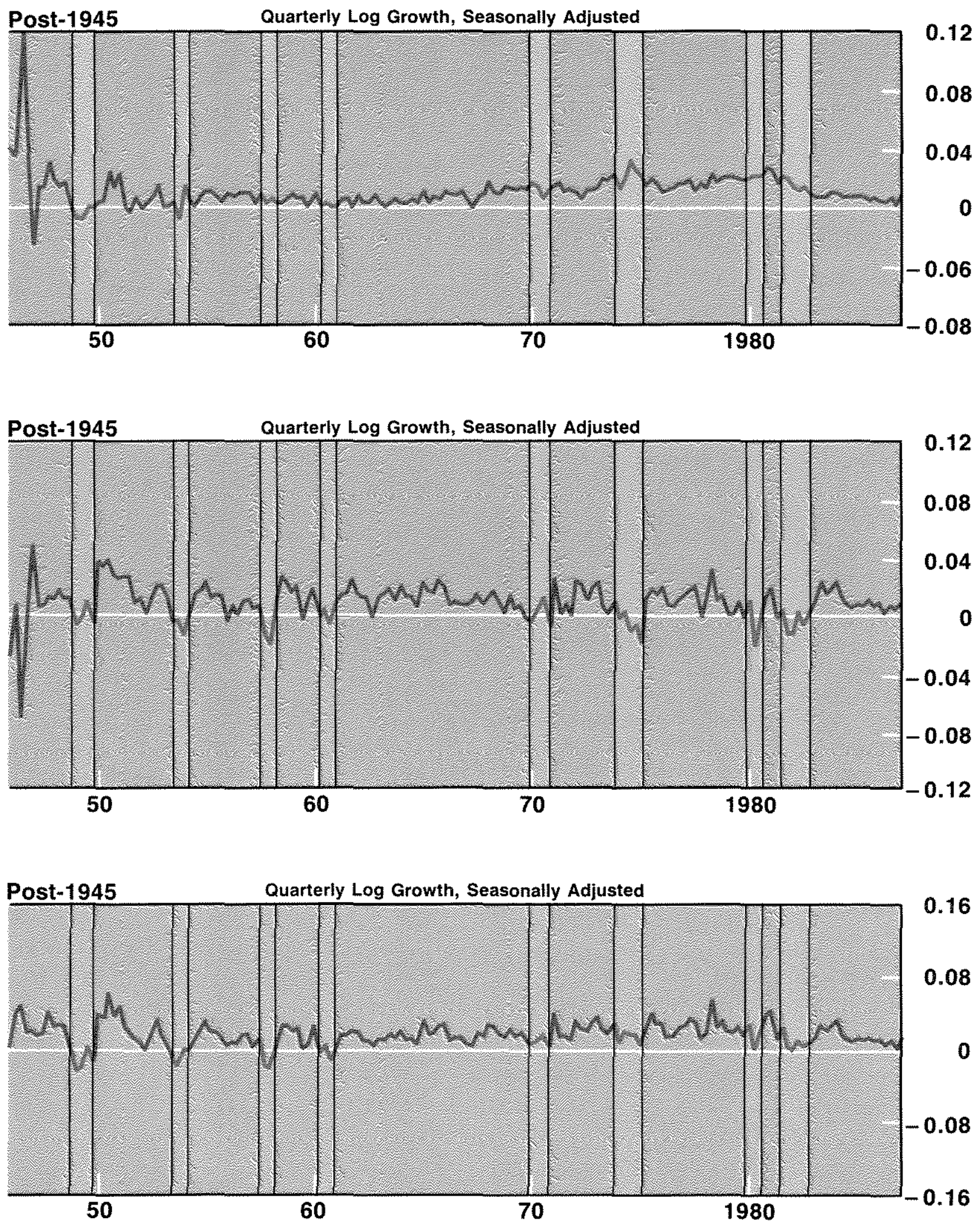
target, it sells open makket securities and forces a contraction in monetary aggregates. As a result, interest rates are prevented from falling as much as if no action were taken.

There are problems associated with interest rate targets, but what about monetary targets? My presentation today addresses whether the relationship between monetary growth and GNP has become so unpredictable as to justify the abandonment of monetary targets which seems to have occurred.

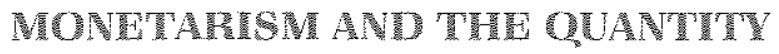 TILOTY}

Monetarism, the apparent heir of the Quantity Theory of Money, was born in the 1960s. Not only was the name changed but also the concept. Unlike the Quantity Theory, whose focus is on the long run, monetarism was widely interpreted as providing an alternative to short run Keynesian model forecasts, a view not always shared by its progenitors

The Federal Reserve Bank of St. Louis equation, which explained quarterly GNP growth largely as a function of monetary growth, became a major monetarist forecasting tool.' Its simplicity and apparent reliability captured the one-dimensional attention of Wall street and Washington. GNP growth was estimated to reflect growth in narrowly defined money, $\mathbf{M}$, in the current quarter and the previous year"; and it was found to rise about 3 percent a year independently of monetary growth. With hindsight, we know that this stable M velocity trend was peculiar to the period on which the estimates were based, initially the 1950 s and 1960 s but then the unfolding 1970 s as well.

The Federal Reserve Bank of St. Louis model went beyond the estimated GNP or demand growth equation to incorporate potential supply growth which together determined inflation and unemployment, and a credit market which determined interest rates." By the end of the 1970 s and into the 1980 s, the weekly publication of M1 changes became a major news event and market force because these data provided a basis for forecasts of total demand growth, inflation and interest rates.

The problem with the simplistic monetarism that afflicted Wall Street and Washington was that it accepted Milton Friedman's dictum that inflation is always and everywhere a monetary phenomenon but not his stipulation that lags are long and variable.

My point today builds on this theme. Monetary policy actions are appropriately directed at longrun stability of the general level of prices but not at offsetting undesired short-term movements in total demand, unemployment, or, for that matter prices. I shall argue that we know enough to keep inflation trends within bounds but not enough to fully stabilize the price level let alone the business cycle. A corollary is that monetarism as a short run forecasting method should be buried; but the Quantity Theory, defined as the predictability of GNP growth on the basis of growth in the monetary aggregates, should be recognized as the correct principle for controlling inflation in the long run; and Federal Reserve operating procedures should be made consistent with that principle.

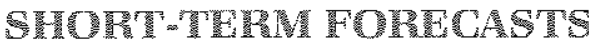

Let me make a few remarks about short-term forecasts. None are very good for very long. Based on Federal Reserve "green" books, Allan Meltzer reports that the Federal Reserve's record of forem casting nominal GNP growth a year ahead over the period 1967 through 1982 had a root mean square error equal to about 60 percent of average nominal GNP growth." Since GNP growth averaged about 10 percent a year, the forecast error is 6 percentage points, indicating that one-third of the time forecasts would miss by more than 6 percentage points and half the time by more than 4 percentage points. Furthemore, and most important, the Federal Reserve forecasts were way off track, missing average growth by more than 5 percentage points, the result of the Federal Reserve persistently underestimating GNP growth during a pe-

1Leonall C. Andersen and Jerry L. Jordan, "Monetary and Fiscal Actions: A Tess of Their Relative Importance in Economic Stabilization," this Review (November, 1968), pp. $1 \neq-24$.

Zeonall C. Andersen and Keith M. Carlson, "A Monetarist Model for Economic Stabilization," this Review (April, 1970), pp. 7-25.

Meltzer, Allan H. "On Moretary Stablity and Monetary Reform" in Y. Suzuki and M. Okabe, eds., Toward a World of Economic Stability (Tokyo: Universify of Tokyo Press, 1988), pp. 51-74. 


\section{Chart 4 \\ Federal Debt and Deficit Ratios to GNP}

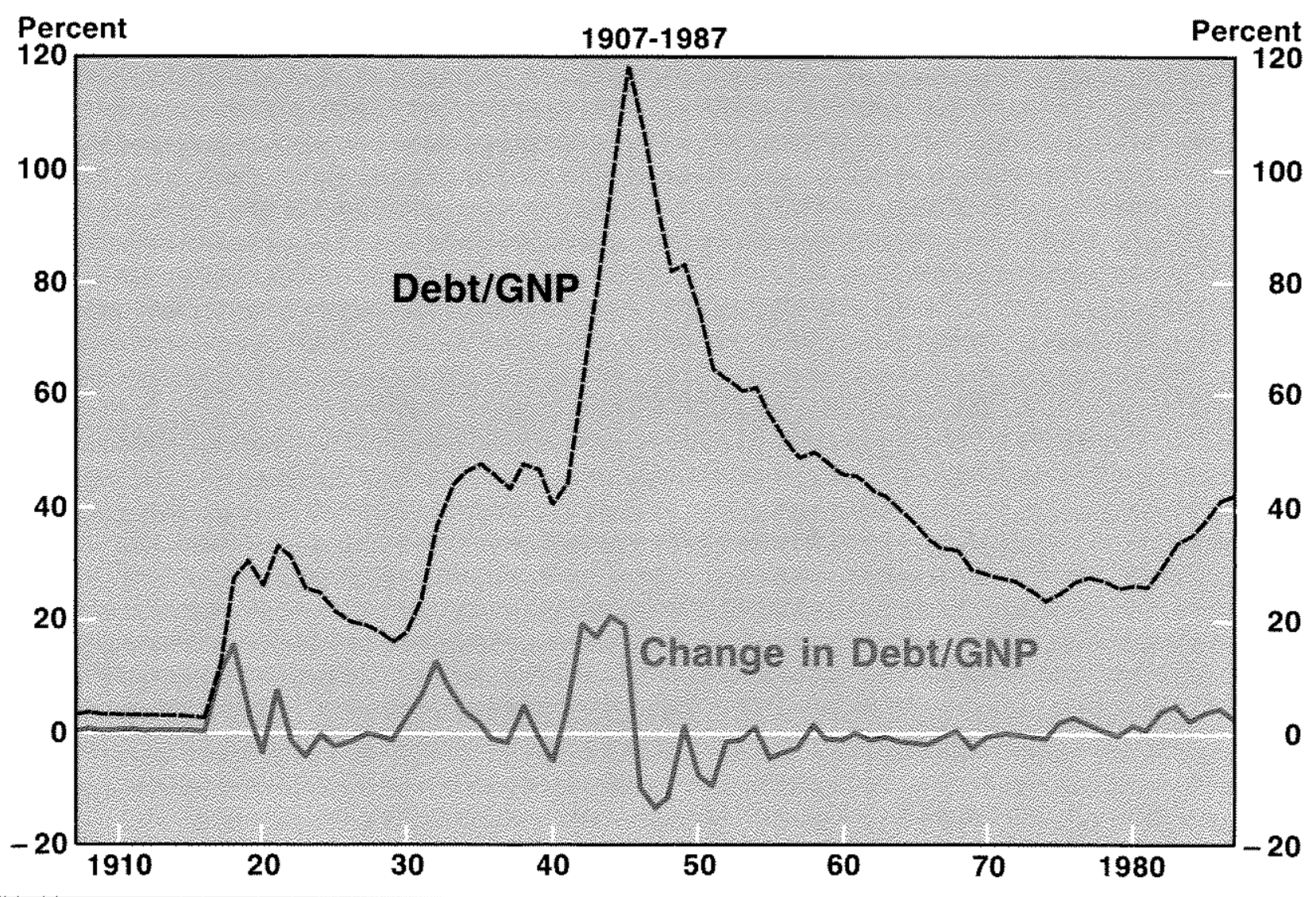

riod of a rising inflationary trend. These striking results are confirmed in an analysis of Federal Reserve forecasting that Karamouzis and Lombra presented at the Carnegie-Rochester Conference last month. They found that the Federal Reserve forecasts systematically underpredicted GNP growth during expansions and overpredicted during contractions. Acconding to Meltzer, private forecasters have had a somewhat better record than the federal Reserve but one still is talking about errors of 4 percentage points a third of the time and nearly 3 percenlage points, half the time. Since inflation is such a lagging factor, changes in nominal GNP growth are initially translated into real growth changes. Hence, errors of 3 percentage points or more in real GNP growth half the time translate into being unable to distinguish reliably between a boom and a recession in either the current quarter or a year ahead.

Melzer was mainly summarizing the performance of non-monetarist forecasts, but one can make at least as critical remarks about monetarist short-ferm forecasts in the 1980s. Like many another forecaster; Milton Friedman's record is blemished. For example, he forecast a recession that didn't materialize in $\mathbf{1 9 8 4}$ and an equally illum sory inflation in 1986. In 1988, not only Friedman but others of comparable persuasion are worried about the consequences of the contraction in monetary growth in 1987

I too am concerned, though it is worth mentioning, as Jim Meigs, an early colleague of Homer Jones at the Federal Reserve Bank of St. Louis, has 


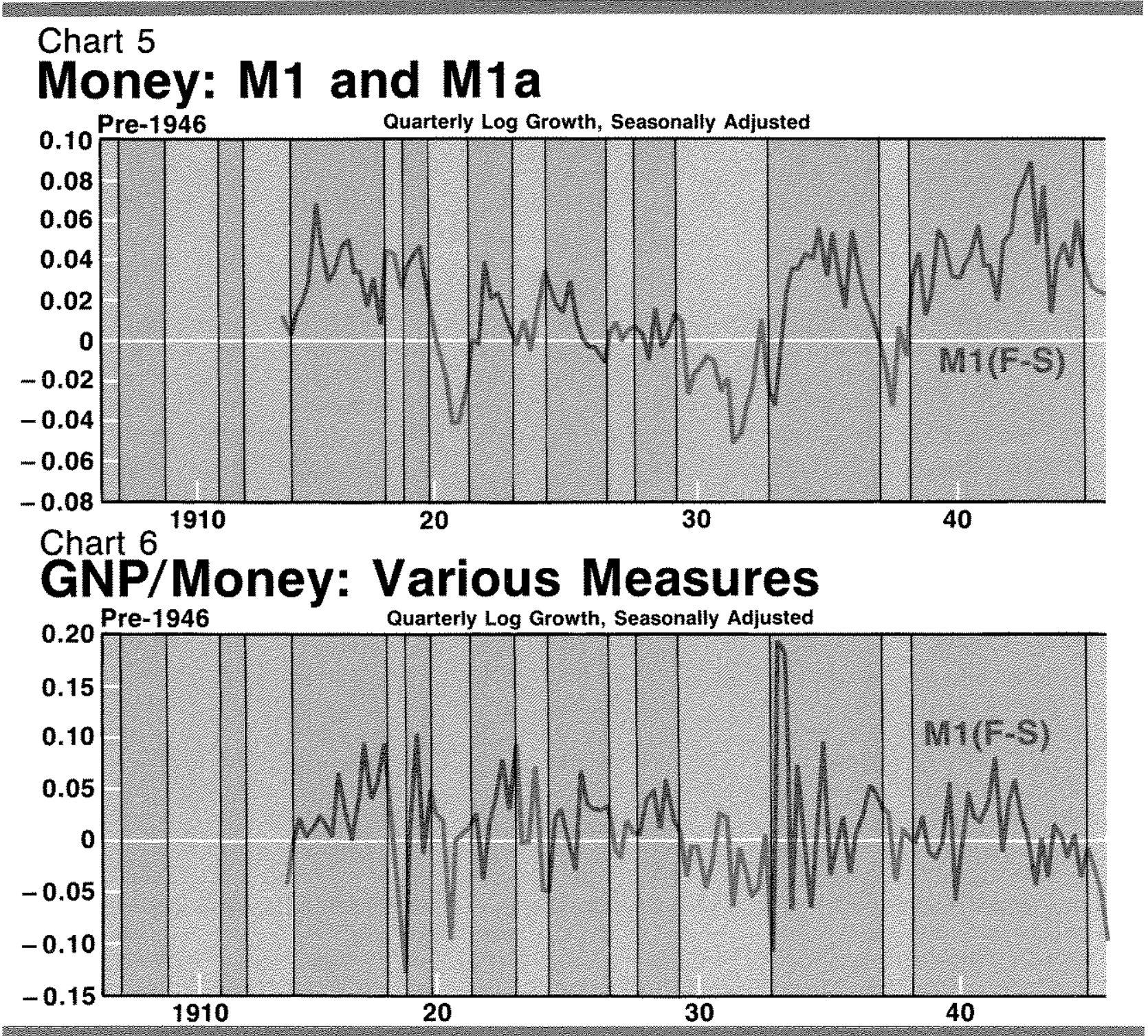

reminded me, that Homer was suspicious about all short-term forecasts, inchuding those based on monetary growth. It was his persistent questioning that created the fluryy of econometric work about monetary relationships for which the Federal Reserve Bank of St. Louis became famous.

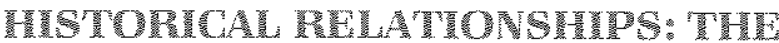 BDOAD PICTURE}

The historical relationship between monetary growth and spending confirms Jones' suspicion. Let me present some charts which put the experience of the 1980 s in perspective.

Chart 1 records inflation in the United States since 1907 , with $1907-45$ and $1946-87$ plotted sep- arately. The blue-shaded areas identify reces sions. Quite clearly inflation was a lot more variable in the initial period, though, because of deflations during recessions in the earlier period, there was no sustained inflation trend as there was in the second period.

Chart 2 plots the real GNP growth rate - a measure of growth in the real supply of goods and services. Though it averaged about 3 percent a year both before and after the end of 1945 , the magnitude of the booms and busts was much greater in the earlier period. Since real growth averaged about as much in each period, it follows that the inflation uptrend in the second period was an aggregate demand not an aggregate supply phenomenon.

Chart 3 presents the nominal GND growth rate 

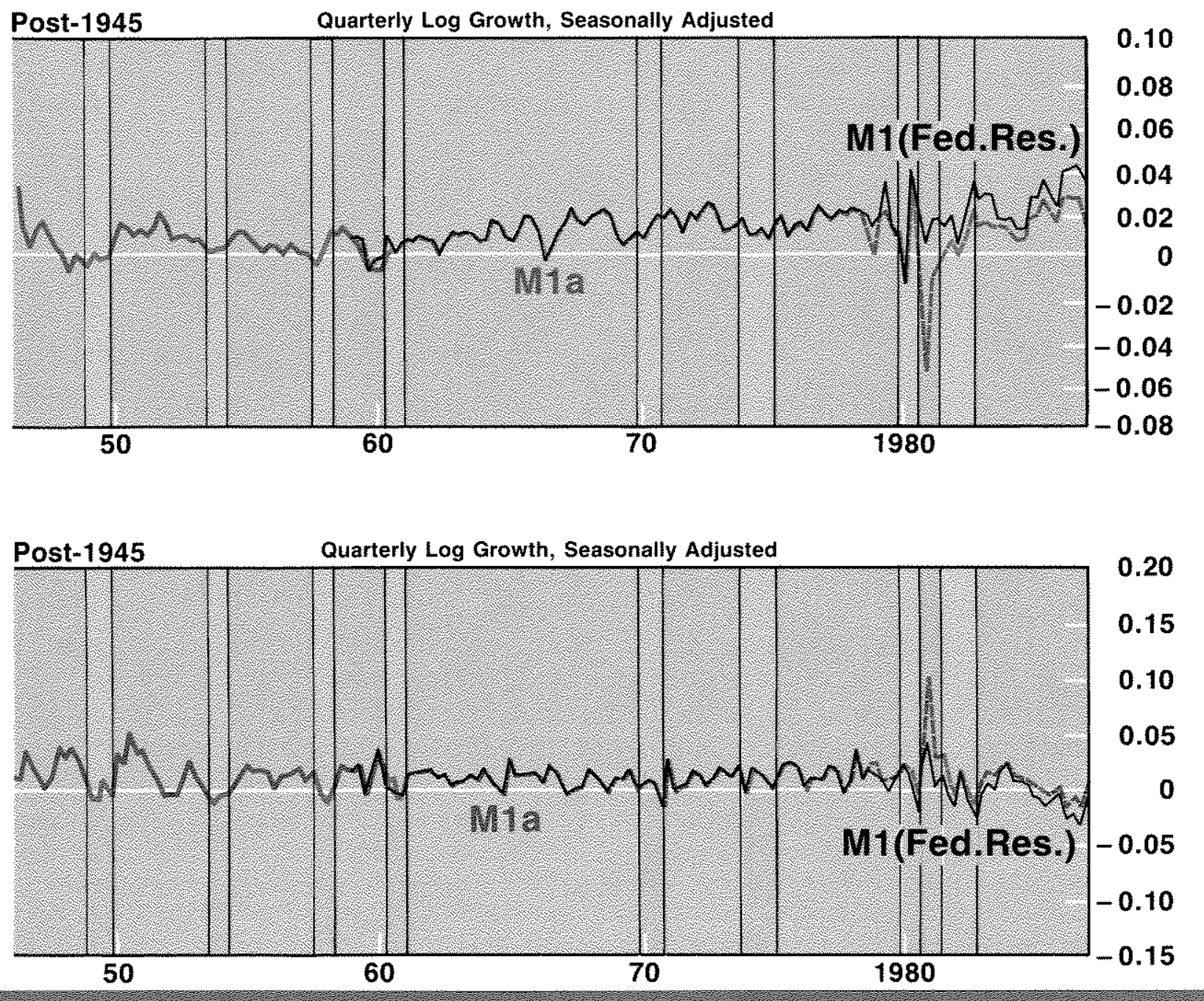

- a measure of growth in nominal demand for goods and services. Though most values are positive, there are some big negatives in recessions through 1960. Since then there has been slowed, not negative, GNP growth during recessions because we have had considerable inflation even in recessions. In terms of proximate causes, Chart 3 shows that slowed GNP growth has always been associated with slowed real growth in recessions, and accelerated GNP growth with accelerated real growth in expansions. Thus, decreased variability in real growth in the post-World War II period is linked to less variability in nominal GNP growth.

What about sources of nominal GNP growth? Conventional wisdom to the contrary, the timing of government spending and tax changes is not systematically correlated with GNP growth. The 1980 s provide a good example. Fiscal policy by every measure was expansionary, yet nominal GNP growth contracted.

Chart 4 plots the ratio of nominal federal debt held by the public to nominal GNP. There is a nominal deficit if the debt rises, but a real deficit only if the debt vises faster than inflation. An increase in the debt to GNP ratio rellects the real deficit rising faster than real growth. The historical record shows that real deficits relative to real GNP did not amount to much before World War I. Big real deficits occurred in both World Wars, the early 1930s, and since 1980 . Since nominal GNP growth accelerated in the wars but decelerated in the 1930 s and 1980 s, there is no consistent rela- 


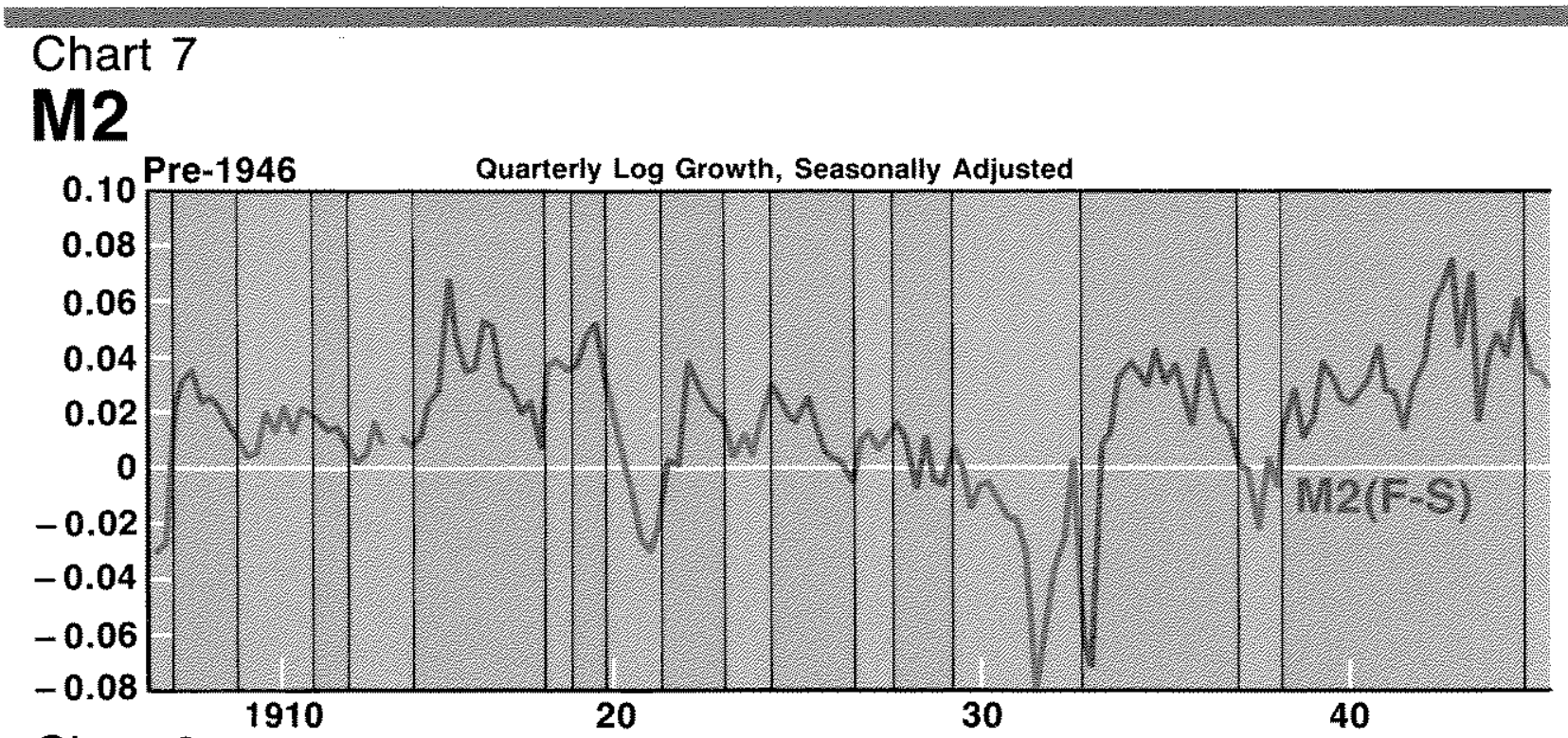

Chart 8

GNP/Money: Various Measures

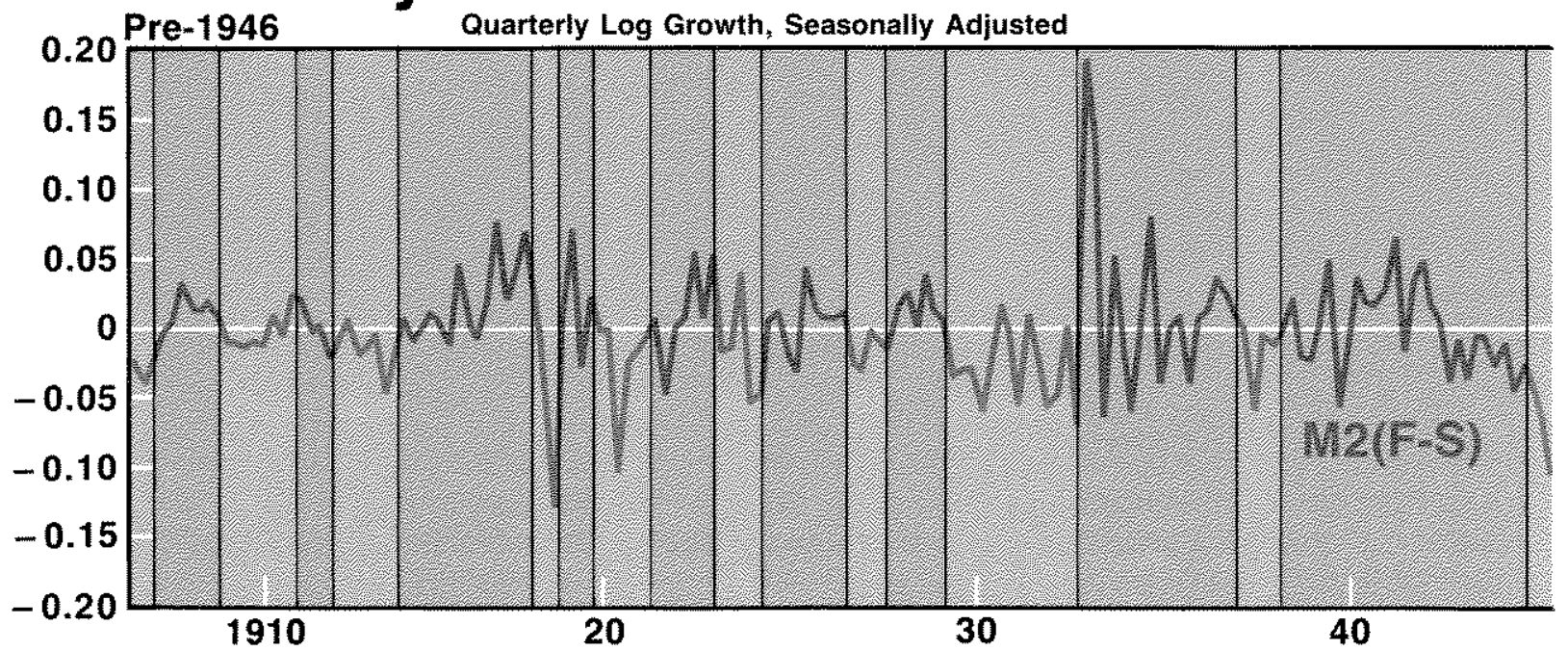

tionship. Furthermore, in the 40 years since the end of World War II, there have been nine business cycle expansions and in only one - the cur rent one - did real deficits rise significantly relative to GNP. Perhaps these official debt figures are the wrong ones to look at because they do not incorporate discounted values of future entitlements and tax receipts. Others might find what they are looking for in these data, but I conclude that there is no consistent relationship between fiscal deficits and GNP growth.

Charts 5 and 6 present the growth rates of the monetary aggregates; M1, M1A and M2. ${ }^{5}$ The record shows that major increases in GNP growth in World Wars I and II were accompanied by both accelerated monetary growth and rising fiscal deficits, and postwar contractions in GNP growth by the reverse movements. Nonetheless, there are

5M1 includes currency and demand deposits; M1A omits deposits that pay interest; M2 adds small time and savings de. posits, overnight repurchase agreements and Eurodollar deposits, and, since 1959, shares in thrifts and money market mutual funds. 

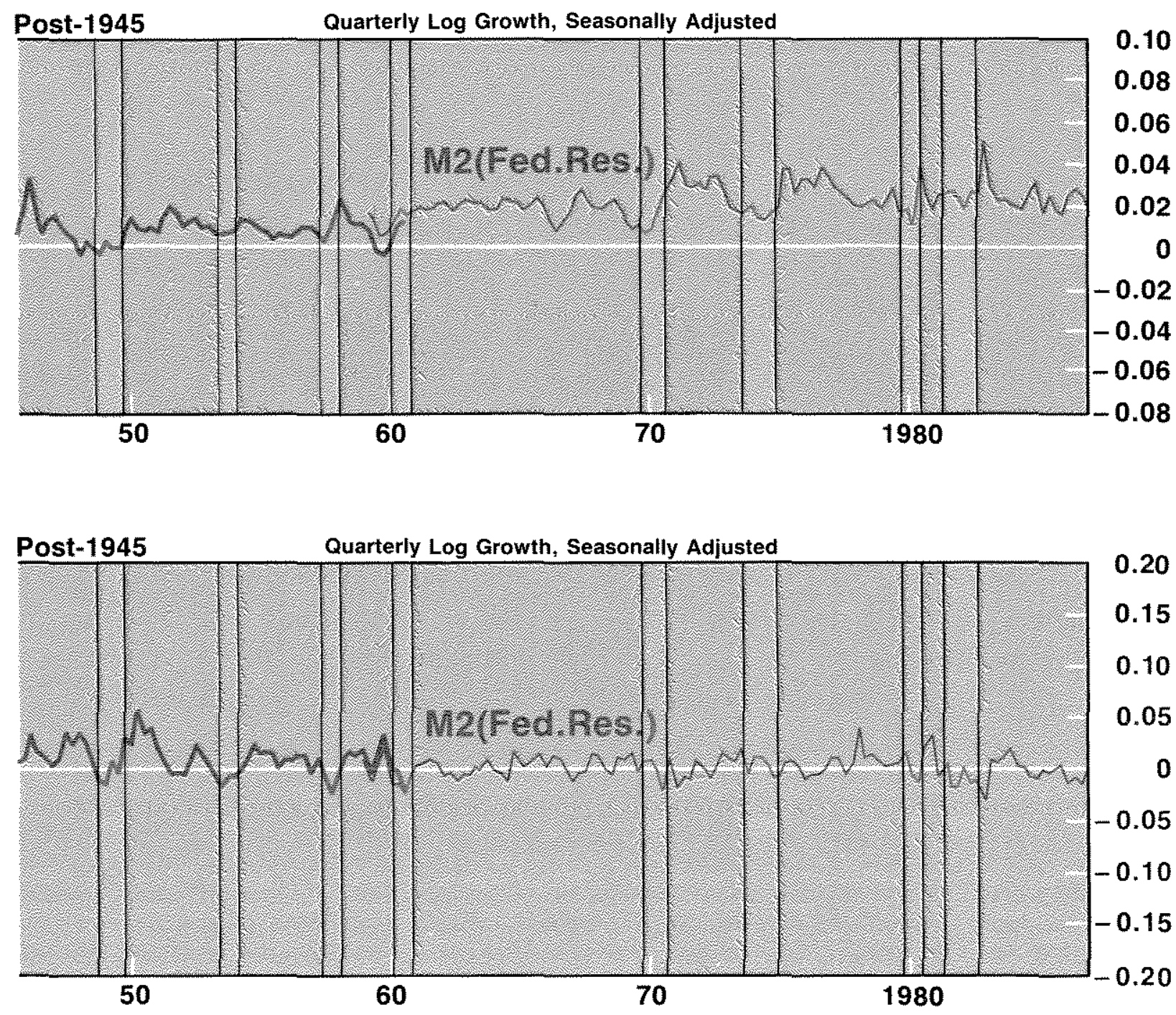

many instances when fiscal and monetary actions pushed in opposite directions. This divergence permits identification of which is the dominating factor affecting GNP growth. In the early 1930s, real federal deficits ballooned but monetary growth collapsed. So did GNP growth. In the 1960s and 1970s, real deficits grew less than real GNP if at all. Monetary growth increased and so did GNP growth and inflation. In particular episodes, such as 1966-67 when real deficits went one way and total spending growth the other, it was monetary growth that tipped the balance.

Charts 7 and 8 present the growth rates in M1 and $\mathrm{M} 2$ velocities. By definition, velocity growth is GNP growth in excess of monetary growth. The charts reveal how steadily M1 velocity increased in the 1950 s through the $1970 \mathrm{~s}$, and how ragged its changes in every other period. The charts also show how $\mathrm{M} 2$ velocity remained largely trendless in comparison with $M 1$ velocity which dipped in the 1930 s but then rose persistently after 1945 until the $1980 \mathrm{~s}$. Note well that in every recession both M1 and M2 velocities fell so that to cushion GNP growth would require faster monetary growth. In the worst recessions, including 198182, monetary growth did not accelerate as velocity growth slowed; and in the worst inflations, including the late 1970s, monetary growth did not decelerate as velocity speeded up. Hence, monetary growth has often been an ineffective counterbalance to moderate excesses in GNP growth. 
Table 1

Average Forecast Errors and Changes in Economic Trends (weighted least squares)

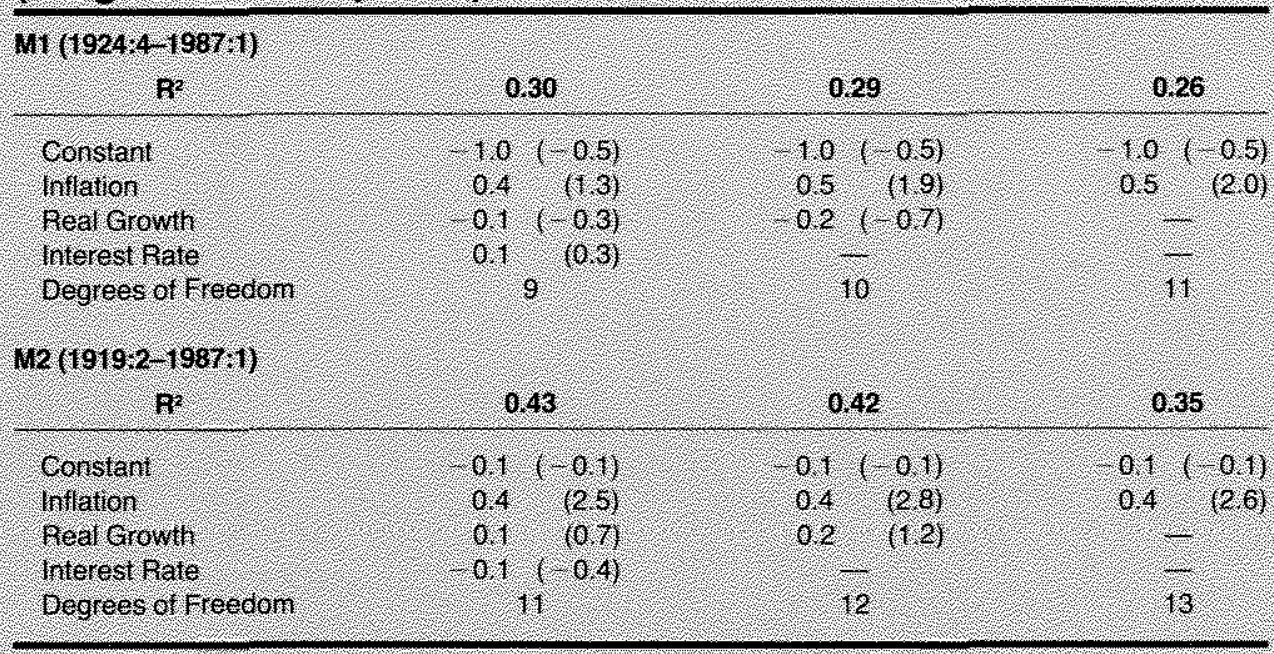

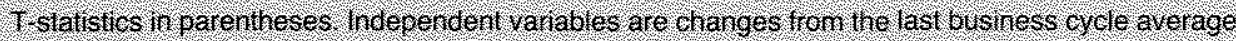
in the estination period to the average tor the for ecast peitod.

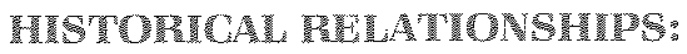 SPECIFIC MOPRCASTS}

William Gavin and I have been studying the quality of quarterly GNP forecasts based on the monetary aggregates. Though there are many studies that have examined the post-World War II period, we were interested in a broader historical experience. Our focus was on out of-sample forecasts we the kind needed to direct monetary aggregate changes to achieve a desired GNP growth path. Quarterly GNP growth forecasts for each business cycle were based on estimates of the relationship between GNP growth and four quarterly lags of monetary growth for the three preceding cycles, that is, a modified St. Louis equation. On the average, both $\mathrm{M} 1$ and $\mathrm{M} 2$ changes were estimated to change GNP growh roughly proportionally while velocity trends were significant in relating M1 but not M2 to GNP. Overall there were 15 forecast intervals for $\mathrm{M} 2$ but ony 13 for $\mathrm{M} 1$. because there was no quarterly information about the split between demand and time deposits before 1914. The first forecast for M1 was the business cycle $1924: 4-1927: 4$.
There are many factors that influence GNP growth. Consequently, in our single equation models that relate GNP growth solely to monetary growth, we expected that shifts in the economy including monetary policy reactions to economic performance would lead to biases in the forecasts. for example, we expected that lower interest rates in a forecast period would decrease velocity and reduce GNP growth relative to monetary growth. To measure the effect of such shifts, we regressed average forecast errors on changes in inflation, interest rates and real growth from the last business cycle in the estimation interval to the average observed in the forecast cycle.

As noted, there was a large decrease in the variance of forecasts from the pre 1946 to the post1945 period. To account for such heteroscedasticity, we weighted observations by the expected standard deviation of the mean forecast errors and then used ordinary least squares to estimate offects of shifts in inflation, interest rates and real growh trends on forecast errors. Table 1 presents the results. The only consistent link to forecast

${ }^{6}$ Gavin, William T., and Willam G. Dewald, "Velocity Uncertainty An Histofical Perspective," U.S. Departmert of State, Bureau of Economic and Business Affairs, Planning and Economic Analysis Staff Working Paper 87/4, November 1987, Gavin was an economist at the State Department in 1987 on leave from the Federal Reserve Bank of Cleveland. 
errors was change in the inflation trend, not interest rates, and not real growth.

Gavin and $I$ also examined cross-country evidence. The results appear in table 2 . We estimated the relationship between annual GNP growth and current and lagged M1 growth for 39 countries for the late 1950s through 1979. GNP growth forecasts for each country were made for 1980-84. As in our U.S. time series analysis, these cross-country GNP forecast errors were strongly correlated with changes in inflation trends, even excluding out" liers such as Bolivia, Brazil, Mexico and Peru that had huge inflation accelerations in the 1980 s.

Why the consistent link to shifts in inflation trends? look at chart 9 . It is apparent that wide swings in interest rates over the business cycle were not closely related to $\mathrm{M} 1$ velocity movements. Furthermore, since real growth averaged about the same before as after the end of 1945, one cannot attribute the persistent rise in M1 velocity until 1982 to that source. Rather, the rise in M1 velocity after 1945 was associated with a persistent rise in the inflation trend.
Table 2
Average Forecast Errors and Changes in Inflation Trends (M1 models only for 39 countries)

\begin{tabular}{|c|c|c|}
\hline & 41 eduntres & Excluging othiers \\
\hline 17 & 107 & 022 \\
\hline Oonstant & 0.8 & 106 \\
\hline Intaton & $00 \% 901$ & $003(2,41$ \\
\hline begressof fregeror & 37 & 33 \\
\hline
\end{tabular}

Countres Australla Austra Belgiun, Bolva, Brazil Canada Colonbia, Denmer, Bomilican nepublic Ecuador. ESalvador f inlard, Frarce, Greece, Guatenala, Jonduras. loeland, lreland, Naly, Japan. Nexico. Netherlands. New Zealand Nonvay Paraguay, Peru. Philpores, Fortugal South Arnca, Spain, Sri Lakka, Sweden Swizertand

Thatland Tukkey. United Kingdom, Uniled States Venezuela, West cermany

Sample perods vay because or data avalabilly but are approximalely 1957,84

\section{Chart 9 \\ Interest Rates and GNP/M1}

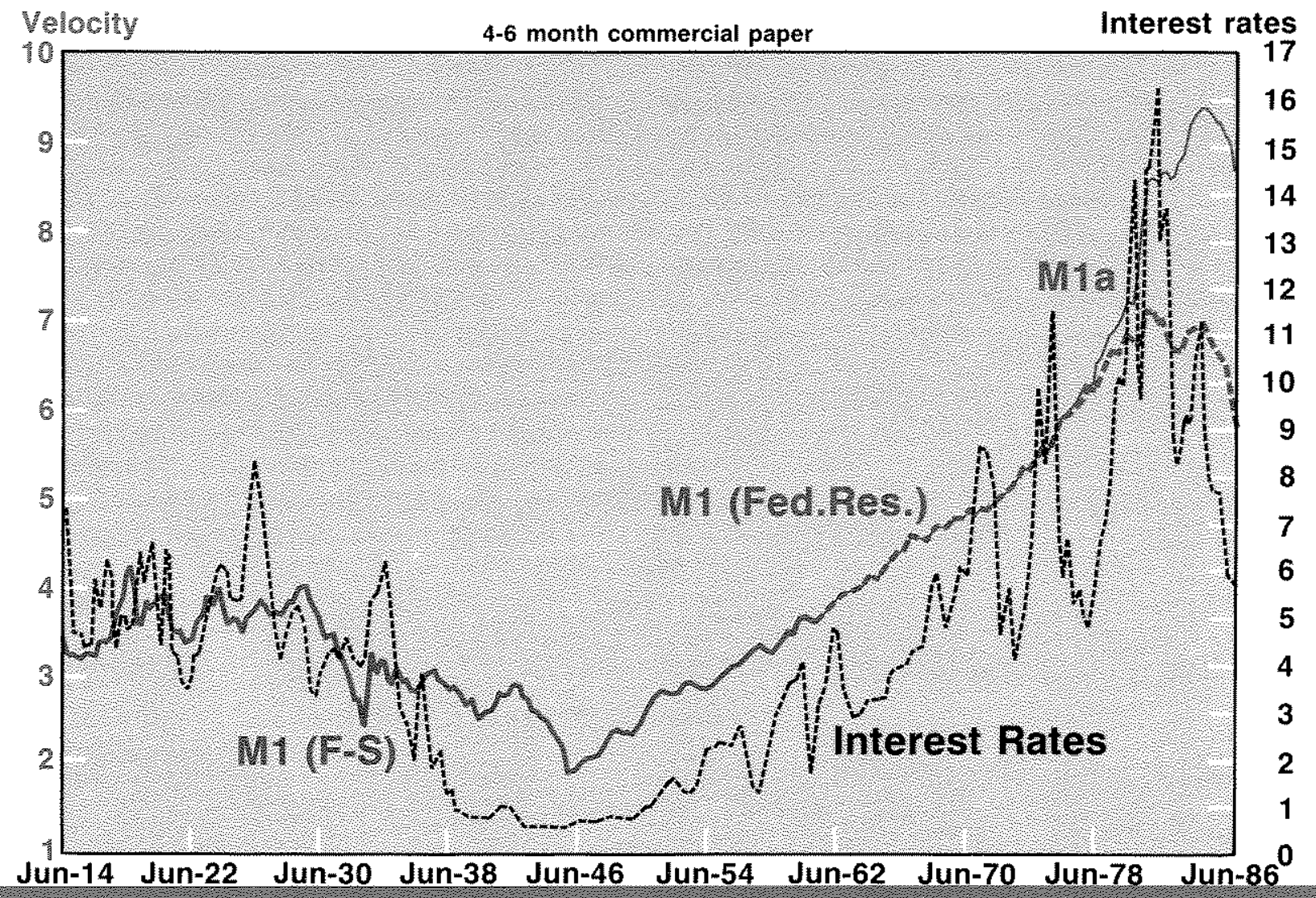




\section{Chart 10 Interest Rates and GNP/M2}

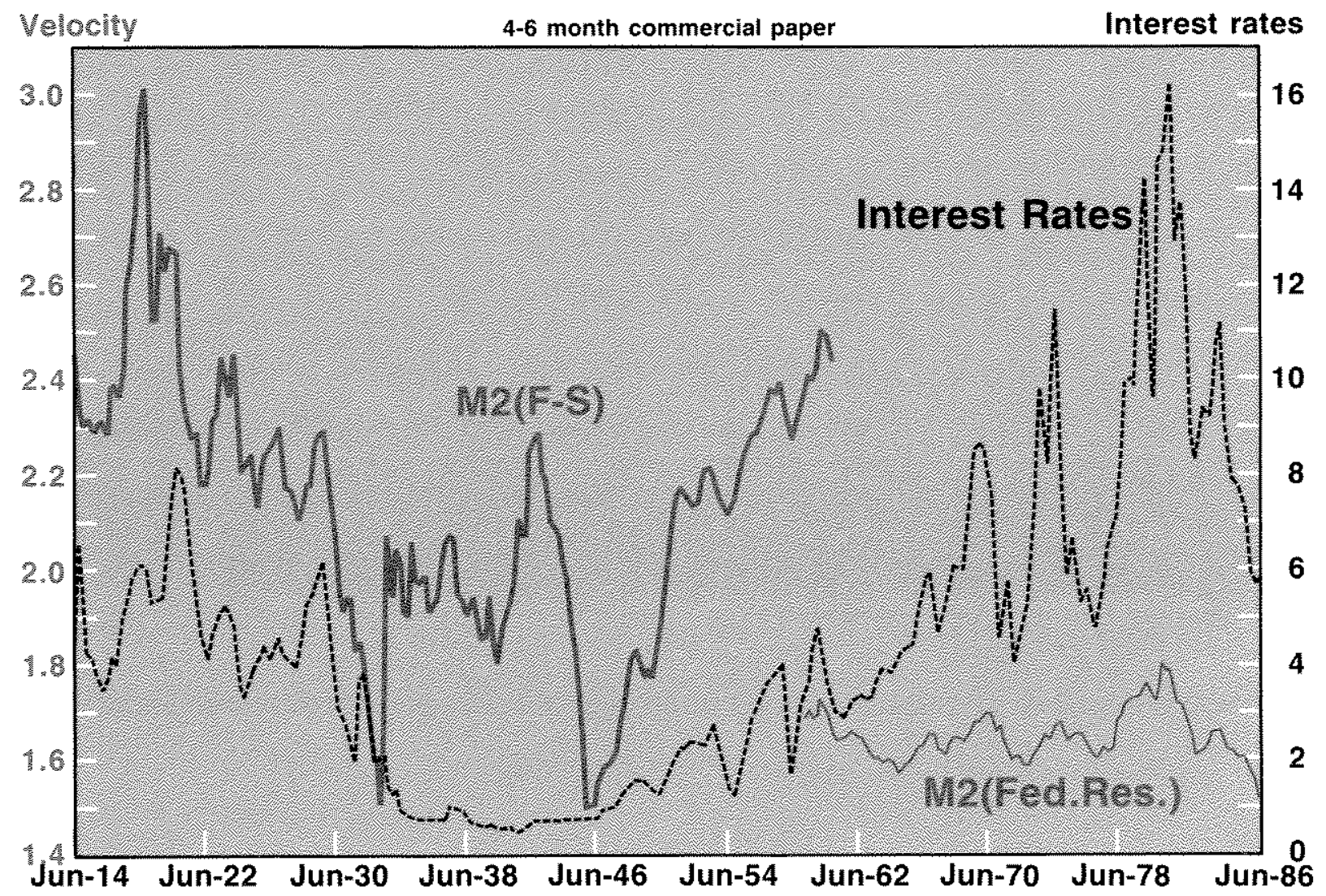

Chart 10 reveals a much weaker association between $M 2$ velocity and interest rates and much less of a trend. The shift in the series is attributable to a redefinition of $\mathrm{M} 2$ in 1959 to include a variety of non-bank liabilities that were not in the Friedman and Schwartz definition.

Chart 11 , which plots only recent data, reveals a close relationship between $\mathrm{M} 2$ velocity and the Treasury bill rate less a calculated weighted average own-rate on M2. ${ }^{7}$ Depository institutions respond to persistent changes in market rates by altering deposit rates, but, even when unconstrained by deposit interest ceilings, adjustments are not that quick or complete. Since the post-war ratcheting up of interest rates reflected an uptrend in inflation, it follows that lags in setting deposit interest rates led to rising opportunity costs of holding M2 balances and to increased M2 velocity when inflation trended up strongly as in 1978-80. In the opposite circumstances when inflation trended down strongly as in 1982-87, falling opportunity costs of holding $\mathrm{M} 2$ balances decreased M2 velocity. Something similar was going on in earlier years too. Thus, Gavin and I found that shifts in inflation trends, but not interest rates, were consistently tied to errors in GNP growth forecasts based on not only M1 but also M2 growth.

Table 3 presents the average GNP growth forecast errors for full cycles based on M1 and M2 growth. Neither totally dominates the other though M2 models were best on average and in

\footnotetext{
'Moore, George, Richard Porter, and Dave Small. "Modeling the Disaggregated Demands for M2 and $M 1$ in the 1980s: The U.S. Experience," Federal Reserve Board Conterence on Monetary Aggregates and Financial Sector Behavior in Interdependent Economies (forthcoming).
} 


\section{Chart 11}

\section{M2 Velocity vs M2 Opportunity Cost 11}

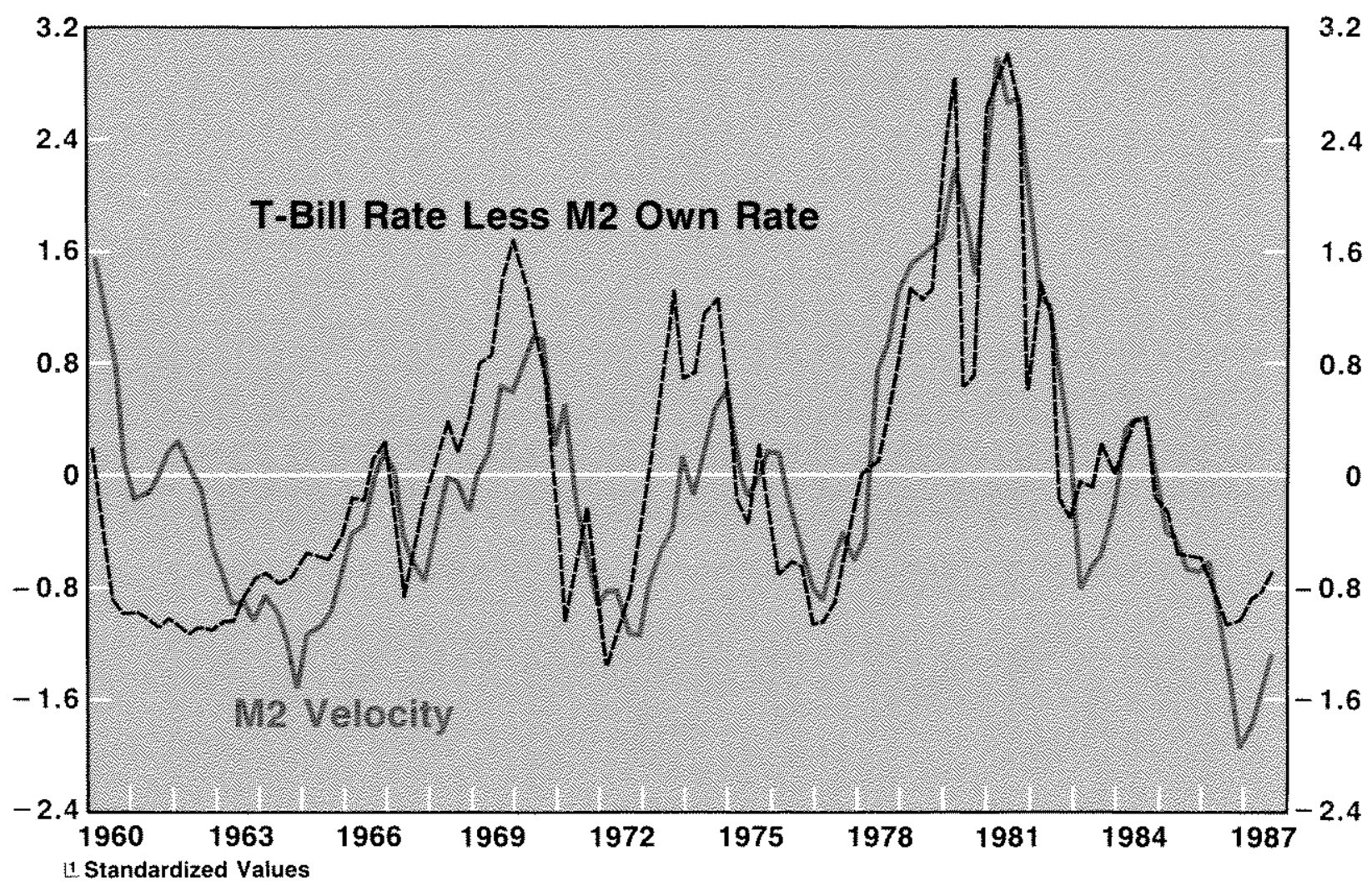

the current cycle. Our finding that forecast errors are smaller for M2 than for M1 or M1A but not by a large margin suggests robustness to the choice of the monetary aggregate. ${ }^{5}$ We also looked at the monetary base and found that M2 models provided the best forecasts on average for both 1907 45 and $1946-87$.

Turning again to table 3 , some forecast errors are huge. Root mean square etrors average 17 to 18 percent in the pre-1946 period, though only about 6 percent in the post-World War II period. By the standards that Meltzer discussed, such errors are comparable to Federal Reserve forecast errors in the "green" book. An inference is that attempts to fine tune GNP growth by controlling either M1 or M2 growth would miss GNP growth targets by more than 6 percentage points one-third of the time and by 4 percentage points half the time. What was said about not being able to distinguish boom from recession holds for our forecasts just as for the Federal Reserve's. However, there is a difference. The average forecast error associated with our simple relationship of monetary growth to nominal GNP growth appears to be well under the reported average errors in Federal Reserve "green" books that Meltzer reported.

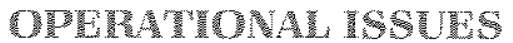

The operational question is what to do in the short run to achieve a long-term inflation objective. Suffice it to say that the Federal Reserve need not iron out every wrinkle in monetary growth to eliminate inflation trends, but it is necessary to tie

\&For a different opinion, see Michael R. Darby, Angelo R. Mascaro, and Michael L. Marlow. "The Empirical Reliablity of Monetary Aggregates as Indicators," Research Paper No. 87 (U.S. Department of the Treasury, 1987). 
Table 3

GNP Growth Forecast Errors Annual Rates of Percent Change

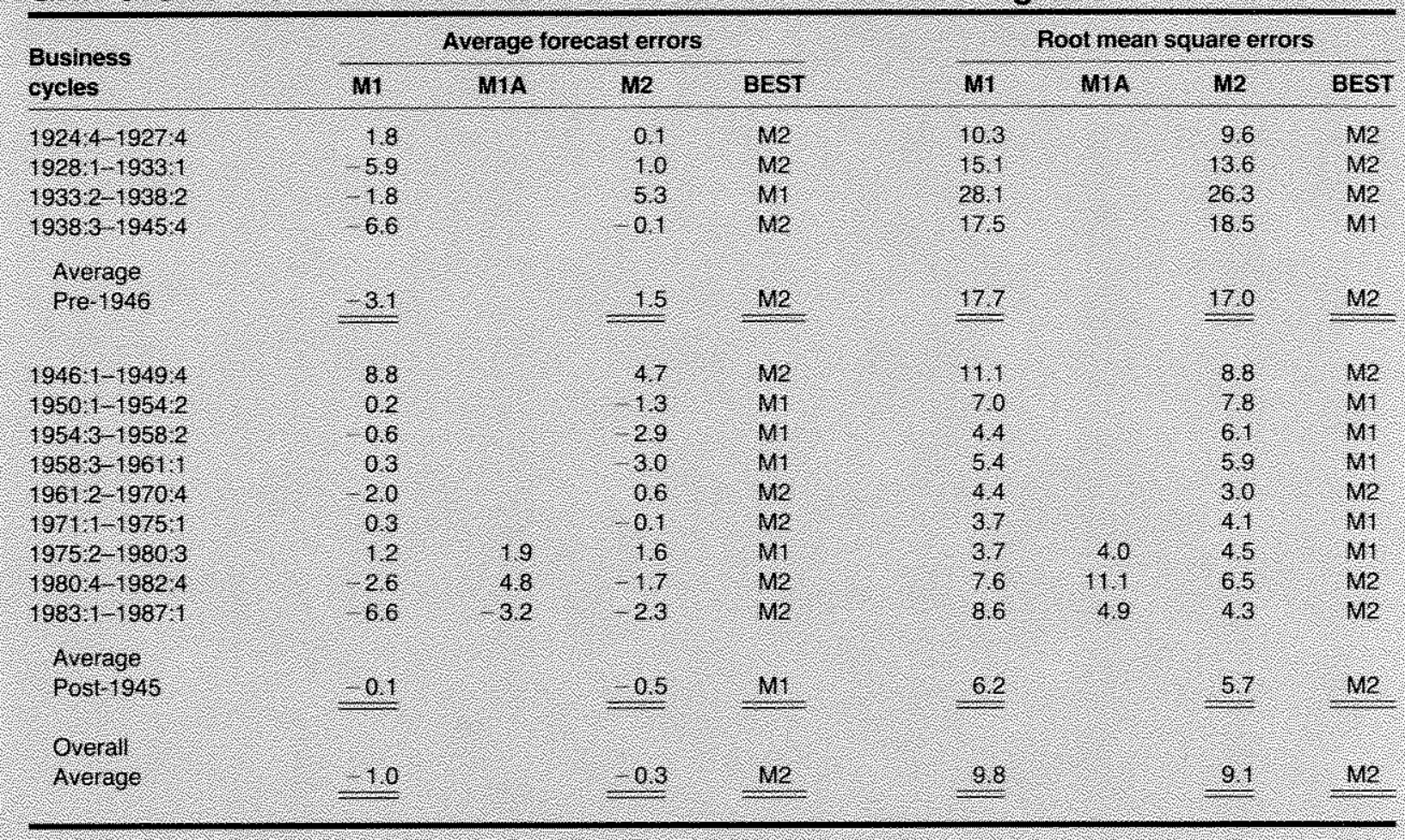

monetary growth to real growth over the medium term to avoid the kind of disturbances that shifts in inflation trends engender. The Federal Reserve needs to adopt systematic operational procedures to shift its policy targets on the basis of observed deviations of GNP growth from desired levels

One way would have the Federal Reserve set a GNP growth target equal to long-ferm real growth plus an inflation target, perhaps zero in the long run but not unreasonably only a partial step in that direction in any one period. The point is not to set monetary targets on the basis of short-rum forecasts of what real and nominal GNP growth is predicted $-m$ I hope I have made clear how errorprone such forecasts are - but rather on the basis of long-run real growth projections plus an inflation goal $_{F}$ not a current GNP forecast."

Such a procedure in the 1970 s would have led to very different results from what we got. The Federal Reserve persistently underforecast GNP growth even as it supplied funds to support accelerating monetary gowth which was reflected in accelerating inflation, higher interest rates, an increasing velocity trend and unexpectedly large GNe growth. Could that sad cycle have been avoided?

Suppose in 1978 , to pick a year, the Federal Reserve had aimed at 3 percent real growth - the long-term average -m and an inflation target 2 percentage points below the 6.8 percent inflation in 1977. Target GNP growth for 1978 would have been 7.8 percent; for $1979,5.8$ percent; $1980,3.8$ percent; 1981 and thereafter, 3 pereent - the long-term average real growth rate.

Fourth-quartel-over-fourth-quarter GNP growth in 1978 was 14.8 percent, not 7.8 percent. GNP growth stayed high: 9.5 percent in 1979 and again in 1980. Inflation accelerated: 7.7 percent in 1978 , 8.5 percent in 1979 and 9.4 percent in 1980. Part of the problem was rising velocity, but the problen

${ }^{9}$ A somewhat similar proposal is found in Bennett McCallum.

"Robustness Properties of a Rule for Monetary Policy,

Carnegie-Fochester Conference Series on Public Policy, Vol.

29 , forthcoming. 
was compounded because the Federal Reserve validated the inflation process by an open market policy that permitted monetary aggregate growth of no less than 7 percent in any of those years and by as much as 11 percent. It was not distinguishing between the wind it was leaning against and the thrust of its own actions.

One cannot be certain about velocity movem ments in the short run but in the circumstances of the late 1970 s with a rising inflation trend, one could have anticipated rising velocities. By whatever means the Federal Reserve might have chosen to control its open market operations - targeting free reserves, federal funds rates, or monetary base injections - over the course of those years it would have had to take actions to restrict monetary growth to prevent inflation from acceleating.

What was required in 1978 , if not sooner, was a genuinely restrictive policy such as we finally got in 1980-81. That policy arrived too late to avoid enomous economic destruction. Inflationary expectations had become entrenched in market contracts denominated in dollars. The costs of disinflation: the worst recession since the 1930s, an overhanging burden of domestic and international debt accumulated on the basis of mistaken price expectations, and a legacy of uncertainty about whether it might not happen again.

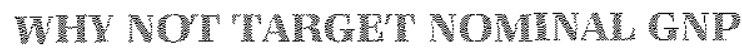 GPON/Th}

It is my contention that putting a GNP target up front for the Federal Open Market Committee to aim at would allow it to mobilze its staff to design the best way to keep monetary growth and GNP growth down when such a course is obviously right as it was in the late 1970s. There is doubtlessly an element of discretionary fine-tuning in GNP targeting but with a twist. Deviations from the target nominal GNe path should induce Federal Reserve actions to move monetary growth up or down in order to bring forecast GNP growth back to a longmun non-inflationary path. Perhaps, there should be some limit on how much change in targeted GNP to be permitted in a particular period. In any case, to avoid getting off track as in the 1970 s, the Federal Reserve has to direct its considerable powers toward controlling inflation trends by actions that push monetary growth in the right direction when nominal GNP growth is off larget.

\section{CONGLUSTON}

To eliminate inflation trends, monetary growth must be kept low on average and close to real growth trends. Extraordinary increases as in 1977 79 or $1985-86$ ought to be avoided so that offetting decreases are not necessitated; but the past is history. What about the future? Certainly we want to avoid another cycle of inflation and disinflation. By luck or design the Federal Reserve in 1987 and early 1988 has pursued policies that are not so different from what $I$ have suggested. Monetary aggregates are growing at about 4 percent annual ates, close to appropriate rates to bring inflation down gradually toward zero. I would hope that the lessons of history could be applied to stay on such a path.

A positive reform to make clear the responsibilities of the Federal Reserve regarding long-term inflation would be to bring it into the federal budget process. Have it announce nominal GNP targets each year on which to base Administration budget projections over the ensuing five fiscal years. Both GNP growth and inflation are critical to the budget with respect to tax receipts and expenditures, particularly interest outlays. Why have the Administration make arbitrary assumptions about GNP growth and inflation as it does now when the Federal Reserve, whose powers are so important in determining nominal magnitudes, could target such values and be held accountable for attaining them? It should take responsibility for what it can control in the medium term nominal spending growth and inflation - and not play meteorologist by leaning against the uncertain winds of the business cycle.

Can we devise ways to create the right incentives for Federal Reserve officials to pursue policies to keep inflation low? The Germans and the Japanese have. In contrast to their success in keeping inflation low, we have gone through the motions of having the Federal Reserve announce monetary target ranges to Congressionat Oversight Committees beginning in 1975 , and since then the worst cycle of inflation and disinflation since World War II. Setting medium-term targets for GNP growth as I have recommended would establish a new responsibility. However, unless the monetary authorities shoulder that responsibility by taking actions to stabilize nominal GNP growth around a medium-term non-inflationary path, nothing would be gained. Establishing yet another target range would make sense only if deviations from it induced stabilizing policy reactions. 
Perhaps, the Federal Reserve must be put on a shorter leash? We could specify a legal limit to the monetary base that the Federal Reserve was authorized to put into circulation in a fiscal yeat. Budget authority is required for the Treasury 10 spend, why not for the Federal Reserve? Then again, it might be somewhat unrealistic to count on Congress to check the inflationary tendencies of the Federal Reserve. An even shorter leash has been suggested by Milton Friedman (and not in jest). He would disband the Federal Open Makket Committee and hire a federal employee to purchase Treasury securities each week as specified by law to keep some monetary aggregate on a long-term zero inflation course. Despite the budget savings in his proposal, wide variation in velocities historically suggests that we might do better than fixing a monetary growth rate in perpetuity.

The fact is that broadly stabilizing monetary policies have been observed on occasion in history. Even during the past decade, some countries have managed their affairs to avoid the worst excesses of inflation and disinflation that we and many other's experienced. We can't repeat history, but we ought to learn from it. In the light of the contribution of Federal Reserve actions to instability in monetary growth, nominal GNP growth and inflation, having it target a non-inflationary nominal GNP growth path over a five-year federal budget cycle would be a step in the right direction. Responsibility for control of inflation would be assigned to the institution that has the most direct power to influence nominal GNP growth and, in turn, inflation. For nominal GNP targeting to succeed in eliminating inflation trends, however, Federal Reserve officials must have the understanding and courage to support the necessary policy actions to get back to a non-inflationary GNP growth path whenever the target is missed. If they did implement such a policy, they would not likely eliminate all the ups and downs in the economy, but they would avoid repeating the most egregious mistakes of monetary history.

\section{DATA BOUROES}

Data used in preparing the charts and statistical study summarized in this lecture came from a variety of sources.

M1 and M2 for May 1907 to December 1958 from Milton Friedman and Anna Jacobson Schwartz, A Monetary History of the United States: 1867-1960, (Princeton University Press, 1963); and January 1959 to March 1987 from the Board of Gover. nors of the Federal Reserve System. Values of M1 were semi-annual until June 1914 and were used in constructing the charts.

Monetary base for May 1907 to December 1918 from Friedman and Schwartz; and January 1919 to March 1987 from the Federal Peserve Bank of St. Louis, adjusted tor required reserve ratio changes but not seasonality. The Census $x-11$ program in SAS was used to seasonally adjust these monthly data from which quarterly averages were calculated.

Commercial paper rate for May 1907 to December 1970 from Board of Governors of the Federal Reserve System, Banking and Monetary Statistics, 1976; and January 1971 to March 1987 from the Federal Reserve Buffetin. Quarterly averages were calculated from the monthly series.

GNP and GNP deflator for 1907:Q2 to 1947:Q4 from Robert J. Gordon, "Price Inertia and Policy Ineffectiveness in the United States, 1890-1980," Joumal of Polifical Economy (December 1982), 1087-1117; and 1948:Q1 to 1987:Q1 from the Department of Commerce, Bureau of Economic Analysis.

All computation were performed on an BBM AT using RATS $P C$ version 2.0 or LOTUS version $2.0 t$.

Data from different sources were spliced by transforming the early series to growth rates and computing revised level series based on actual levels of the most recent series.

The original data used in the Gavin and Dewald study are available from the author on a LOTUS spreadsheet upon request with an acompanying $5 \% / 4$ inch diskette and a stamped, self maddressed disk mailer. 